\title{
Educación Física e ideología. \\ Creencias pedagógicas y dominación cultural en las enseñanzas escolares del cuerpo Physical Education and ideology. Pedagogical beliefs and cultural domination in the school education of the body
}

\author{
*Miguel Vicente Pedraz \\ *Universidad de León (España)
}

\begin{abstract}
Resumen: Este artículo aborda el contenido político e ideológico de la educación física. Una materia escolar cuyo discurso didáctico, amparado en la verosimilitud que expresa la relación técnica entre medios y fines (pedagógicos), ofrece una imagen de neutralidad y de asepsia ideológica que las representaciones sociales dominantes del cuerpo parecen corroborar: el cuerpo entendido como estructura orgánica y anatómica. La creencia en la sustancialidad del cuerpo y de la propia disciplina académica ha ido configurando toda una serie de estructuras pedagógicas y, asimismo, todo un cuerpo argumentativo y de prácticas que hacen de ella una disciplina prácticamente infranqueable a la crítica, salvo en cuestiones superficiales de su puesta en escena, que da lugar a situaciones educativas paradójicas, tal vez, inadmisibles en otras disciplinas y contextos. Con estos supuestos el objetivo del artículo es poner de relieve alguno de los mecanismos de construcción de estas creencias, identificar las relaciones de poder que sustentan dichos mecanismos y cuestionar la practicidad del curriculum que como resultado ofrece el discurso técnico legitimado.
\end{abstract}

Palabra clave: educación física, ideología, poder, subjetividad.

\begin{abstract}
This article addresses the political and ideological dimension of physical education. The didactic discourse more specific of physical education, as a school subject, relies upon the technical relationship between pedagogical means and ends, and, therefore, offers a rather neutrally ideological image of those social representations that most define the body as an organic and anatomic structure. The belief in the substantiality of the body and in physical education as an academic discipline itself has shaped a large series of educational structures as well as a whole body of arguments and practices, all meant to convert physical education in a discipline virtually above any attempt of criticism, except for certain superficial matters, rather paradoxical and, probably, hardly acceptable in other disciplines and educational contexts. With these assumptions, the objective of the article is to discuss some of the mechanisms of construction of these beliefs, to identify the power relations that sustain these mechanisms and to question the deficiency of practical sense of the curriculum that as a result legitimizes the technical discourse.
\end{abstract}

Key words: physical education, ideology, power, subjectivity.

\section{Introducción}

Algunas de las viejas discusiones epistemológicas y la búsqueda de reconocimiento pedagógico, que hasta los años ochenta ocupaban en España y su contexto próximo un lugar de privilegio en el debate de la educación física (Cagigal, 1979; Grupe, 1976; Parlebas, 1987; Rodríguez, 1988; Sergio, 1988; Vázquez, 1986; Vicente, 1988) parecen habercedido definitivamente en favor de debates de carácter más doméstico, a menudo, destinados al consumo masivo de los profesores. Los discursos que pugnaban por la consideración científica de la disciplina, a veces con mucha vehemencia pero no siempre con suficiente consistencia argumentativa, no constituyen hoy un ámbito de preocupaciones significativo; así, cuestiones entonces frecuentes como la del estatus epistemológico, los referentes teóricos, el paradigma al que debía o podía adscribirse y, sobre todo, la identificación o definición de «su objeto» de estudio, con los que además se esperaba legitimar la materia escolar, parecen suscitar en este momento muy poco entusiasmo investigador. Al menos, muy poco en comparación con el interés que despierta la tecnología didáctica, siempre resuelta a satisfacer las necesidades prácticas de los profesores avocados a la inmediatez de tener que enseñar algo a los escolares y de enseñarlo bien.

En este contexto, más allá de las disputas entre sensibilidades y concepciones didácticas diferentes que, en ocasiones, han dado lugar a modelos y paradigmas de educación física que entre sís se han considerado antagónicos, la mayoría de los trabajos de esta área han apelado y apelan de manera recurrente al cambio, la innovación, la transformación, la superación, la alternativa curricular, etc. respecto de la que la mayoría de los autores denominan educación física tradicional; algo que sin duda pone de manifiesto, además del entusiasmo didactista, el celo innovador y también, en parte, la percepción que muchos tienen del agotamiento pedagógico de la vieja disciplina.

Fecha recepción: 06-03-09 - Fecha envío revisores: 06-04-09 - Fecha de aceptación: 20-11-09 Correspondencia: Miguel Vicente Pedraz

Facultad de Ciencias de la Actividad Física y del Deporte

Universidad de León. 24071. León

E-mail: mvicp@unileon.es
Por otra parte, la oportunidad política y administrativa de introducir en el debate académico de la educación física algunos de los modelos enseñanza desarrollados, fruto de las emergentes líneas de investigación didáctica, $\mathrm{y}$, eventualmente, la posibilidad de ponerlos en práctica a través de los programas de educación física escolar, han supuesto, paradójicamente, mayor impulso legitimador para la educación física que los antiguos debates sobre el objeto de estudio; desde luego, mayor reconocimiento que los discursos sobre los fundamentos científicos de la materia y, también, mayor estabilidad curricular que la búsqueda del estatus epistemológico. Tal vez, la razón de ello estribe en la propia naturaleza de la producción didáctica, cuya verosimilitud técnica ofrece una sencilla, pero firme, imagen de practicidad y de «apego a la realidad» sustentada en el poder de convicción que despliega la visualización de la relación instrumental entre medios y fines; algo que ha podido impregnar la opinión pedagógica y obrar al servicio del reconocimiento político y social de un estado de cosas curriculares que ya aparece como natural y por ello, también, como indiscutible.

Sin embargo, dichas líneas de investigación didáctica-y el discurso técnico en el que se apoya-, incluso cuando se postulan como innovadoras o alternativas, antes que asumir una perspectiva crítica, tanto de alcance particular como global, del ejercicio educativo y antes que solícita a los grandes problemas y discusiones que ha planteado y sigue planteando la pedagogía, se han resignado a elaborar sucesivas propuestas donde ha primado el acopio de actividades novedosas sobre la modernización de las estructuras y las mentalidades pedagógicas; donde ha imperado la proliferación de estrategias sobre la adecuación de los métodos y de los contenidos a la nueva realidad escolar y, sobre todo, a la nueva realidad social. Es decir, donde han prevalecido las formas sobre el fondo según unos criterios de banal eficiencia que obstaculizan toda posibilidad de conformar una materia escolar de carácter emancipatorio orientada al desarrollo de capacidades críticas y deliberativas respecto de los usos del cuerpo donde las habilidades corporales concretas tendrían una significación vital y una utilidad existencial más allá del ludismo complaciente. En cierta forma, han actuado como dispositivos ideológicos que han contribuido muy estrechamente al mantenimiento de las relaciones de poder. 
Pues bien, lo que a este respecto trato de plantear es profundizar en dichos dispositivos; analizar algunos de los principios y categorías, concepciones y representaciones, que desde el discurso técnico didáctico- definen los contenidos de enseñanza y, a la vez, le dan el sentido y la legitimidad pedagógicos que en la actualidad posee. Como tarea fundamental, procuraré identificar los principales tópicos discursivos, las creencias y las supuestas verdades positivas en torno a las cuales se constituyen y justifican los paradigmas dominantes en educación física; se trata de descubrir en qué medida las nociones más indiscutibles que definen la educación física se formulan y se desarrollan como inferencias derivadas de una practicidad constatable o, por el contrario, son estructuras estructurantes, esquemas de saber previos, que demarcan arbitrariamente el alcance y los límites de la disciplina al margen de una pertinencia pedagógica objetivable en términos de proyecto y fines educativos plausibles.

De acuerdo con estos objetivos, es preciso señalar aquí que adopto una perspectiva sociogenética de corte constructivista según la cual toda realidad social se concibe como un producto histórico, pero de acuerdo con un tipo de análisis que pone el acento en la interdependencia de discursos, instituciones e individuos entre sí en la producción de la realidad. A este respecto, aunque serán dispersas y hasta deliberadamente diversas las referencias teóricas, como herramientas conceptuales básicas que sirvan a los propósitos de este artículo, tomo de Norbert Elias, además de la idea de «configuración», la noción de «poden» como relación asimétrica de interdependencia; de Pierre Bourdieu, la dimensión simbólica del «orden social» y con ella las nociones de «capital simbólico, social y cultural» y su relación con las nociones de «campo» y «habitus», además de algunas de sus formulaciones a propósito del sistema escolar como agencia reproductora de las desigualdades sociales; de Berger y Luckman, la noción de universo simbólico y su relación con los procesos de institucionalización y legitimación; de Michel Foucault las nociones de «esquemas» o «regímenes de verdad», «tecnologías del yo» y «gubernamentalidad».

\section{Legitimación del discurso téenico y sus producciones 2.1. El sustancialismo como creencia pedagógica}

Tal vez una de las creencias que más contribuyen a la legitimación del discurso técnico de la educación física y sus producciones es el que se puede denominar tópico sustancialista, el cual, posiblemente, ampara y da sostén a otras muchas creencias pedagógicas. Consiste [el tópico sustancialista] en la consideración de la disciplina como el resultado de un «proyecto natural» que habría emanado de unas necesidades objetivas, naturales, sustanciales y, por lo demás, preexistentes de educación del cuerpo; unas necesidades que explicarían su temprana aparición como acontecimiento antropológico y, asimismo, las sucesivas modalidades de acuerdo con las distintas circunstancias culturales. Se trata de una consideración que se adhiere a la historicidad de la disciplina -incluso enfatiza su condición evolutiva- pero que, sin embargo, concibe el proceso histórico de manera lineal, unidireccional y finalista, además de perpetuo, sobre la creencia positivista de la permanencia (sustantiva) del cuerpo y la confianza en el desarrollo infinito de la historia y de sus objetos. A este respecto, el relato histórico de la educación física al uso traspone a épocas pretéritas y a civilizaciones clásicas escenas típicas de la educación física actual y viceversa, con lo que, además de afirmar su universalidad, provee a la disciplina de una procedencia prestigiosa que le confiere legitimidad como forma de intervención pedagógica.

Según Norbert Elias $(1978,1989,1990)$, el sustancialismo -que, como ya expresara Wittgenstein (1994), consiste en la búsqueda de una sustancia que responda a un sustantivo-determina el hecho de considerar a priori que tras las palabras que empleamos existen realidades perfectamente definidas, sustancias, cosas visibles y tangibles, realidades, en cierto modo, atemporales que, por lo demás, son independientes de la conciencia. En la práctica, se abre paso como una corriente antihistórica en la medida en que da carta de naturaleza «natural» a todo lo nombrado $-\mathrm{y}$, se diría, que sólo a lo nombrado-, donde el lenguaje cumpliría el papel de fedatario de una realidad que, con matices, tiende a ser considerada como «dada» y, por lo demás, dicotómica: sujeto/objeto, individuo/sociedad, cuerpo/espíritu, físico/social, real/imaginario, etc. Lo que aquí nos interesa destacar es que se trata de una concepción de corte funcionalista según la cual las realidades -también las socialesestarían sometidas a un ajuste orgánico cuyo funcionamiento estaría asegurado por una especie de relación solidaria entre los distintos elementos que la componen (conceptos, saberes, creencias, representaciones, cosas, sujetos, grupos de sujetos, instituciones, etc.), los cuales parecen orientados según cierto sentido finalista y determinista al equilibrio del propio sistema: la realidad tiende a ser lo que «es», y viceversa, es lo que «tiende a ser». Contra esta concepción, Elias (1990) propone utilizar las armas de la historia y, en particular, la sociogénesis y la psicogénesis de la cultura; con la demostración de la relativamente tardía aparición de entidades tan aparentemente incuestionables como nuestra imagen del hombre, nuestras concepciones familiares e, incluso, las nociones de sociedad o individuo, tiempo, cuerpo, etc., - -todas ellas elaboradas sobre una problemática típicamente occidental y modernano sólo pone de relieve el carácter contingente de la realidad sino que, sobre todo, nos advierte de las trampas que la historiografia de corte evolucionista puede tendernos: especialmente, la cosmovisión finalista de la civilización. En este sentido, para él, el devenir histórico de la humanidad se origina en múltiples proyectos, pero sin proyecto, y se dirige a múltiples finalidades, pero sin finalidad: «Nacido de planes, pero no planeado; movido por fines, pero sin un fin» (1990, p. 84).

Pues bien, la consideración más común de la educación física incurre precisamente en esta trampa historicista que a la postre, según veremos, ampara cierta clase de discurso técnico, sobre todo el didáctico, en cuya verosimilitud encuentra buena parte de su justificación pedagógica. En virtud de la relación solidaria y armónica de todo sistema, la educación física como institución, pese a no estar exenta de desequilibrios, tendería a la «normalización» o permanente reequilibrio, con lo que su proceso de transformación histórica se entendería como una evolución funcional en sentido estricto; como una paulatina equilibración «natural» de los medios y de los fines educativos del cuerpo a lo largo del tiempo. Bajo esta perspectiva, las distintas modalidades o versiones que en cada cultura, en cada civilización o en cada momento histórico hayan podido tener lugar, no serían sino simples adaptaciones al contexto -o la mera modernización de prácticas- de algo que en el fondo, en su esencia, tendría la misma sustancia y habría estado ya presente-prefigurado-en el pasado remoto. En el caso de la educación física contemporánea, el alto grado de racionalidad-supuestamente avalado por las disciplinas científicas que la asisten-bastaría para certificar su pertinencia pedagógica entendiéndose que sería la versión mejor ajustada a las necesidades sociales actuales de acuerdo con los medios técnicos disponibles.

Frente a la concepción de las realidades sociales como precipitados quasinaturales, Elias (1989) aborda la cuestión de la génesis de las instituciones desde una perspectiva constructivista según la cual toda realidad se concibe como conjunto de producciones genuinas de una cierta cultura y de un cierto tiempo, aunque, evidentemente, como resultado de previas construcciones históricas. Sin embargo, y a diferencia del historicismo, la perspectiva constructivista pone el énfasis en las acciones de los actores individuales y colectivos concretos en situaciones concretas, de modo que la pluralidad de intenciones, de significados, de formas de apropiación de las preconstrucciones pasadas, etc. da lugar a un entreveramiento de relaciones que, al no surgir necesariamente de una voluntad clara, ni de una naturaleza dada, tiende a escapar al control de los diferentes actores implicados (y de la propia historia). Lo que ello implica, a diferencia de los modelos sistémicos y funcionalistas, es que hace descansar el significado y la pervivencia más o menos armónica de la realidad social y de cada una de sus instituciones no en las nociones de cohesión, integridad o unidad funcional, etc. -lo que le impone soportar y dominar algunas contradicciones epistemológicas-, sino en la noción de legitimidad; ya no se puede hablar de una armonía orgánica ni de una totalidad sistémica a priori en el seno de las instituciones sino de un trabajo simbólico a través del cual adquieren una cierta coherencia discursiva (Bergery Luckmann, 2003) que impone reconocer una relación de poder. 
Para el caso que nos ocupa, el constructivismo nos induce a pensar la educación física escolar como una configuración contingente, incluso fortuita y casual -dentro, evidentemente, del marco de posibilidades que ofrecía el contexto en el que apareció- fruto de condiciones, intenciones e intereses más o menos confluyentes de algunos grupos hegemónicos en torno a unas preocupaciones sociales nuevas según un proceso en el que unos significados, y las consiguientes prácticas, adquieren respaldo -se tornan dominantes-y otros lo pierden. En este sentido, la disciplina académica, más que dar continuidad tecnológica a una «predisciplina» habría de entenderse como una realidad emergente resultante de una confrontación de representaciones diferentes, a menudo en pugna, a veces en cierta sintonía -entre lo nuevo y lo viejo, entre lo culto y lo popular, entre lo religioso y lo profano, entre lo racional y lo tradicional, lo institucional y lo espontáneo, el saber y el hacer, etc.-, las cuales, sin sustancia ni proyecto definido le fueron dando forma como tal disciplina académica. Por mejor decirlo, fueron construyéndola, como disciplina escolar, por acumulación, sustitución, sustracción, transformación, etc., donde las justificaciones funcionales se habrían ido elaborando incluso a posteriori de su configuración como una condición más de entre las que eventualmente fueron interviniendo en su génesis. Los casos de la inclusión del deporte en las public school inglesas de mediados del siglo XIX, de la gimnasia filantrópica en las escuelas de centro-Europa por la misma época, o del juego en los jardines de infancia algo más tarde, son paradigmáticos porque ponen de relieve la escasa importancia que en un principio se concedió a unas y otras prácticas en sus respectivos entornos como actividades educativas propiamente dichas y, sin embargo, una vez incorporadas, el discurso pedagógico encontró solícito las justificaciones técnicas pertinentes para que los materiales culturales de las élites fueran asumidos y naturalizados por el sistema. Parece claro, a este respecto, que a los miembros de la clase obrera del siglo XIX y principios del XX les interesaba poco que sus hijos practicaran deporte o gimnasia en la escuela; no parece tampoco que estuvieran muy atraídos por el juego pedagógico (que aprendieran jugando, jugaran para aprender, aprendieran como si jugaran o jugaran a que aprendían algo); les interesaba que estuvieran a cubierto y que adquirieran los rudimentos intelectuales y de hábito más elementales. Serían los dirigentes de la burguesía acomodada, con una idea muy diferente de la infancia y con preocupaciones en torno a la distribución de un tiempo académico que debía ocupar tanto tiempo como la jornada laboral, la que propiciaría, no sin conflictos, la lenta incorporación de actividades no prácticas en la escuela $\mathrm{y}$, eventualmente, su sistematización en el campo de la educación física: deporte, gimnasia y juego, introducidos inicialmente como actividades diversivas quedarían incrustados y, a la postre, definidos como ingredientes elementales de una educación física escolar que ya siempre llevaría la impronta de la sensibilidad corporal y gusto de la clase dominante (Clement y Herr, 1993; Fauché, S., Callède, J.-P., Gay-Lescot J-L. y Lapagne J-P.2000).

Si las nociones del constructivismo son válidas para el análisis del proceso de conformación de los contenidos y de la propia idea de educación física, no son menos válidas en lo que respecta a la definición del elemento primario sobre el que la educación física interviene: el cuerpo. En realidad, la noción de cuerpo y la filosofía subyacente a las ideas de cuerpo «educado», cuerpo «instruido», cuerpo «formado» (o «bien formado») constituyen el basamento más firme sobre el que opera históricamente la evolución de la materia escolar; pues bien, esa noción y esa filosofía subyacente son lo suficientemente inconstantes y veleidosas como para que podamos atisbar casi de un golpe de vista lo a-sustancial de la disciplina en el curso de la historia.

La hipótesis que a este respecto se plantea es que la educación física constituye, antes que nada, un dispositivo administrativo del buen gobierno corporal; es decir: el resultado más organizativo que pedagógico de nuevas preocupaciones respecto del sujeto y la gestión de la subjetividad en el seno de una sociedad dominada ya por la moralidad burguesa en la que el cuerpo, que siempre se había mantenido en un dificil equilibrio cultural, empezaba a cobrar protagonismo, no sin traumas ideológicos, en la definición de la identidad (Corbin, 1991). En este sentido, antes que como un mero desarrollo de las soluciones técnicas tradicionales a las necesidades de aprendizaje corporal y antes que como solución técnica novedosa a problemas nuevos, se plantea la emergencia de la educación física como la creación de una forma políticoadministrativa difusa de entre las muchas que puso en práctica la modernidad como mecanismo de ordenación y control social entre las que, sinduda, destacaron las políticas de higiene proletaria, la reordenación urbana, los decretos antisubversión, la ficha policial de identidad universal y, como no, la reordenación de las políticas asistenciales y de escolaridad donde el control y la vigilancia eran las preocupaciones prioritarias (Foucault, 1991, 2005). Dicho de otro modo: planteo que la aparición de la educación física escolar, antes que una respuesta pedagógica ante necesidades de aprendizaje y desarrollo físico constatable, es la resultante de una conjunción de estrategias diversas y dispersas destinadas a limitar los extravíos del régimen normalizado de la virtud; unas estrategias que fueron encontrando cabida en los establecimientos escolares donde la necesidad de llenar tiempos, distribuir espacios, aplacar la efervescencia corporal de la infancia poco habituada a la quietud, etc., obligó a incorporar prácticas académicamente heterodoxas, no sin conflictos de orden pedagógico, y a amalgamar contenidos, métodos e idearios que le dieran legitimidad.

\subsection{Dominación simbólica vs funcionalidad práctica}

Haciéndonos eco de la terminología de Berger y Luckmann (2003), diría que la lectura constructivista fija la atención en los procesos sociales a través de los cuales las instituciones llegan a ser objetivamente disponibles y subjetivamente plausibles en el seno de un determinado universo simbólico. En todo caso, el concepto de «legitimidad» remite a la idea de apropiación que empleara Norbert Elias (1978, 1989, 1990) para referirse a los modos en que tiene lugar el proceso de la civilización de las costumbres y, por extensión, el proceso mediante el que se configuran las relaciones interindividuales: desde el comportamiento mesurado a la mesa hasta la adopción de una determinada postura «higiénica» o «saludable» en el pupitre o en el lecho, pasando por la continencia emotiva y corporal del sujeto en las relaciones con los demás o consigo mismo, nada de lo cual es absolutamente natural o producto de un escrúpulo natural (Elias, 1989). No son, apunta, producciones técnicas que hayan surgido con un objetivo funcional o práctico claramente reconocible, sino que van consolidando su forma, delimitando su función muy lentamente y regularizándose su uso a través de las distintas capas sociales mediante un mecanismo de apropiación de abajo arriba o de arriba abajo, no sin tensiones culturales y sociales, en el que las significaciones se van modificando de acuerdo con los rasgos predominantes del círculo social en el que se instalan. Lo significativo del planteamiento de Elias (1990) es la perspicacia interpretativa del proceso civilizatorio en términos de configuración social, en el sentido de que nos permite comprender cómo la aparición y consolidación de cualquier comportamiento en el curso de la civilización suele obedecer, antes que a una solución técnica razonada ante un problema práctico dado, a una pugna simbólica entre tendencias emotivas e ideológicas contrapuestas, así como disputas de identificacióndiferenciación social mediante la adopción (por invención o por apropiación) de expresiones físicas, ideas y sentimientos inéditos o raros, delicados, exquisitos, etc. y, asimismo, a la incorporación de pautas de relación y trato paulatinamente más complejas, elaboradas y autocontroladas.

La conformación de las instituciones sociales en tanto que mecanismos de regulación, tipificación, habituación o de administración del comportamiento en diferentes órdenes y campos, no sólo no escapa a este análisis sino que incluso resulta paradigmática por cuanto las reglas por las que se rigen los miembros que integran dichas instituciones obedecen a la misma lógica de interacciones e interdependencias: el trabajo o la lucha simbólica por la legitimidad. Más aún, es en el proceso de conformación histórica de las instituciones (la sexualidad, el tiempo, la ciencia, la familia, el deporte, la educación, el derecho, la lengua, el dinero, etc.), que el racionalismo presenta como exteriores y trascendentes a los individuos, donde según los planteamientos constructivistas se 
configura la identidad (individual, colectiva, infantil, femenina, masculina, proletaria, burguesa, corporal, étnica, etc.) en tanto que incorporaciónno electiva y en gran parte inconsciente- del «habitus dominante» del grupo de pertenencia; es decir, en tanto que interiorización de disposiciones duraderas, estructuras estructurantes (Bourdieu, 1991), que adquiere el individuo en el proceso de socialización, las cuales suponen una inclinación determinante a percibir, sentir, pensary actuar de manera cuasi instintiva.

Bajo esta perspectiva, la consideración del carácter funcional que explícitamente expresa el discurso técnico de la educación física escolar -donde las justificaciones (utilitarias) aparecen como avales de su pertinencia institucional (véase, Fernández-Balboa, 2003; Kirk, 1990; Devís, 1996) se revela, cuando menos, problemático. En efecto, el cometido que dicho discurso atribuye a la materia como condición necesaria y garante del desarrollo de cualidades físicas o de competencias y habilidades en los distintos ámbitos del comportamiento del sujetofísico, social, emocional, intelectivo, moral, etc.--pierde el más importante de sus sustentos epistemológicos por cuanto las propias nociones de cualidad o capacidad fisica, competencia, habilidad, incluso desarrollo infantil e infancia, etc., junto con todas las que modernamente han engrosado el vocabulario pedagógico de la educación física (autonomía, autoconocimiento, autosuperación, autorrealización, salud, etc.) se muestran relativas y contingentes; se muestran válidas tan solo en el interior esquemas de verdad dominantes y de acuerdo con los desiderata prácticos de los grupos hegemónicos. Dichas nociones dejan de aglutinar esa clase de sustancia indiscutible de la categoría «educar el cuerpo» para revelarse como categorías fuertemente convencionales aunque, eso sí, prevalentes, puesto que de hecho han logrado conferirle legitimidad curricular y social mediante una dinámica interna de creación de conocimiento tecnológicamente explotable. Para ello, una buena parte de los esfuerzos discursivos han debido ocuparse en ocultar el carácter convencional de dichas categorías dotándolas, mediante la aplicación sistemática del saber positivo y de la razón instrumental, de una apariencia de practicidad -al servicio de la funcionalidad orgánica- que permite a las estructuras de poder consolidarse en virtud de su carácter «natural».

Resulta clarificador lo que Wright Mills (1999, p. 93) calificaba como «practicidad liberal» a propósito de la filosofía moral del utilitarismo y los modos de legitimación del poder; justamente se refería a esa clase de concepción de la utilidad cuya metafísica «orgánica» 0 «natural»como la que parece legitimar a la educación física-subraya todo lo que tiende al equilibrio armonioso y donde los cambios o no se advierten o se toman como meros síntomas de lo «patológico» o «inadaptado», es decir, se toman como una desviación de la naturaleza que es preciso corregir y en cuyo auxilio acude la técnica. Mills incide en el carácter conservador de la practicidad liberal, la cual, frente a la practicidad antiliberal, controladora, disciplinaria y orientada al lucro industrial, resulta simpática a aquellas personas que por su posición social, y en virtud de algún grado de autoridad, manejan casos individuales (jueces, trabajadores sociales, higienistas mentales, maestros, etc.) los cuales tienden a pensar de acuerdo con las «situaciones» concretas, a resolver problemas prácticos siguiendo los patrones existentes, lejos de cualquier controversia ideológica y de cualquier intento de interpretar y, mucho menos, de transformar el conjunto. Evidentemente, puesto que descubrir problemas prácticos y enunciarlos es hacer valoraciones, la practicidad liberal no es ajena a la moral ni es apolítica; se configura como una sociología moralizadora en la que se toma como problema aquello que se aparta de lo común, lo que no se ajusta a los principios de orden y estabilidad; es especialmente moralizadora cuando dichos problemas se enuncian en relación con las instituciones respecto de las que se supone necesitan mayores dosis de racionalidad (científica o técnológica) sobre principios del tipo logro de la estabilidad y el orden, el progreso social, la adaptación, la integración, etc. -como por ejemplo la escuela, la medicina, la cultura- que con frecuencia constituyen, señala Mills (1990, p. 104), «una propaganda a favor de la conformidad con las normas y rasgos idealmente asociados con la clase media de la pequeña ciudad».

Tal vez se puedan extraer de esto algunas consideraciones sugerentes para interpretar la educación física escolar en tanto que institución sustentada en un alto grado por el discurso didáctico, cuya practicidad liberal (racional, funcional y sistémica) termina por otorgarle carta de naturaleza «natural», categoría de dato empírico-legitimidad científicalejos de toda discusión sobre los elementos ideológicos, políticos e, incluso, morales que median en la acción pedagógica del cuerpo.

No se nos puede escapar que todo discurso que interpreta y concibe las «cosas del mundo» las ordena y las clasifica de un modo contingente, casi siempre con verosimilitud lógica y, a menudo, con suficiente fuerza persuasiva como para hacer de sí un modelo de percepción, una estructura de significaciones, de valoraciones y de acción; es decir, con capacidad para construir el «mundo de las cosas». Pues bien, bajo una bien elaborada argumentación lógica y clasificatoria, el discurso pedagógico de la educación física -y las consabidas prácticas en las que se sustenta-no es ajeno a esta condición de estructura estructurante, como lo es, por otra parte, cualquier discurso sobre cualquier materia escolar en su respectivo ámbito de representaciones. En el que nos ocupa, se configura como una estructura estructurante de la corporeidad pedagógica $\mathrm{o}$, si se prefiere, del sujeto corporalmente educable para lo cual aplica los parámetros de sistematicidad, calificabilidad, homogeneidad, etc., que imponen los modelos tecnocráticos propios de la institución escolar. Pero dicho discurso, en la medida en que construye el cuerpo educable y legitima sus atributos (el cuerpo hábil, eficaz, sano, diligente, aseado, atento, obediente, experimentado, etc.), en la medida en que hace visibles $\mathrm{y}$ «verdaderas» ciertas condiciones de «ser cuerpo» no sólo resiste la prueba de las argumentaciones sino que a menudo puede resistir la prueba de los hechos; $y$ es que el mundo de las representaciones no es sólo un mundo de imágenes, es el mundo que construimos y que aceptamos, es «el mundo» (Berger y Luckmann, 2003): el universo posible (y el no posible) del cuerpo como objeto de intervención educativa cuyos límites reconocibles la autoridad pericial no permitiría traspasar, so pretexto de mantener la «esencia» de la materia. Algo que refuerza de tal manera la tradición profesional y el discurso pedagógico oficial que no sólo hacen imposible el cambio, sino que cualquier crítica que vaya más allá de la mera alternativa de contenidos o de métodos es tachada de irracional o de extravagante.

Pues bien, siendo la categoría «educar el cuerpo» una entidad fuertemente convencional, aunque legítima, dicho universo posible-la institución del cuerpo como objeto de tratamiento escolar-debe soportar, según apuntaba en el apartado anterior, algunas contradicciones para contener y dominar su sentido dentro del marco funcionalistasustancialista en el que obtiene su reconocimiento. En otras palabras, debe lograrque los significados por los que dicha institución es reconocida como agente social útil o funcional en el ámbito en el que dice serlo (el desarrollo necesario de habilidades y capacidades corporales de los sujetos) mantengan su credibilidad, a pesar de aquellas argumentaciones, teorías, evidencias, pruebas, etc., que los pongan en tela de juicio o que, simplemente, revelen el carácter relativo, incluso arbitrario, de las categorías pedagógicas y sociales en las que se apoya. Ahí, a la insidiosa verosimilitud argumental del discurso técnico, cuya tenaz relación entre medios y fines parece inexpugnable, se une la acomodaticia ambigüedad de los sucesivos discursos pedagógicos institucionales del cuerpo, pergeñando un aparato de creencias bien adaptado a los saberes dominantes (sobre todo de la biología y la psicología del desarrollo), bien adaptado a la tradición positivista y de fácil sedimentación en el sentido común; al menos, de fácil sedimentación en el sentido común de los enseñantes de la educación física. Veamos algunas de estas contradicciones y las creencias (funcionalistas) en las que se sustentan, al amparo de la ideología pedagógica dominante.

\section{Creencias pedagógicas en la Educación Física como} dispositivo de la ideología dominante

Tal vezla más elemental contradicción que la educación fisica escolar ha de soportar para contener su significado en el marco funcionalista es la que tiene que ver con la corporalidad que dice producir y la que, de hecho, produce. De acuerdo con el carácter contingente y convencional de la disciplina académica, antes que enseñar al cuerpo, la acción primera 
de su propia legitimación ha sido necesariamente la construcción del cuerpo apto para ser enseñado; es decir, escolarmente enseñado. Ha debido configurar, siquiera esquemáticamente, las condiciones en las que el cuerpo puede y debe ser enseñado dentro de la escuela; ha debido perfilar los límites del universo posible de la intervención pedagógica sobre el cuerpo así como una batería de justificaciones plausibles. Pues bien; a tenor de las cosas que se le enseñan, cómo se le enseñan y cómo se han ido estableciendo tales enseñanzas a lo largo de su breve historia, parece que dicho universo pedagógico ha sido elaborado no tanto bajo la premisa de qué es lo que conviene aprender al cuerpo, a los cuerpos, y para qué, como por la necesidad de encontrar un lenguaje adaptado a lo que ya se enseñaba; un lenguaje técnico que autoriza y acredita el tratamiento institucional del cuerpo sin levantar sospechas de llevar a cabo un ejercicio coercitivo, de dominación cultural o de inconfesable moralización; es decir, donde la elaboración de las justificaciones a propósito de lo ya dado, de lo «esencial», han prevalecido sobre los intentos de transformary adaptar lo establecido a las nuevas expectativas sociales. A este respecto, la educación física, antes que explorar las necesidades de los cuerpos individuales, los cuerpos-sujeto, ha producido un discurso polivalente y ambiguo, un discurso acomodaticio, que, en el momento actual, superadas las funciones diversivas y descompresoras que antaño cautivaron a los promotores de la educación física, se sostiene bajo la ilusión pedagógica de la transferencia de las competencias físicas, la ganancia de eficacia o de salud que tanto seduce a la racionalidad instrumental. Aquí cabe distinguir dos tópicos; el primero consiste en la formulación de una cada vez más abigarrada mezcla de propiedades formativas y reformativas en la que acaba encontrando acomodo todo género de utilidades, atributos y objetivos de acuerdo con los discursos imperantes; me referiré a este tópico con la denominación de «capitalización intensiva de propiedades». El segundo de los tópicos, la «desubjetivación del cuerpo», tiene que ver con la consideración de este como un objeto natural y neutro, vacío de contenido, donde la educación física vendría a llenarlo de capacidades, habilidades, aptitudes, etc. también consideradas naturales y neutras-mediante un diseño didáctico pericial es decir, mediante un diseño tecnológico que encuentra acomodo en la concepción sustancial de la infancia y su desarrollo evolutivo que, a la postre, relega a la mínima expresión los condicionantes sociales y de «capital cultural» en el diseño y ejercicio de la educación física.

\subsection{Capitalización intensiva de propiedades}

En cuanto al primero de ellos, como para apuntalar un endeble edificio discursivo que no es capaz de sostener la materia académica sobre el inconfesable cometido de transmitir una parte del capital cultural hegemónico del cuerpo mediante la inculcación de ciertas habilidades fisicas y el autodominio corporal, ha debido desarrollar todo un andamiaje teórico por el que, bajo los ambiguos emblemas de la «formación del carácter», la «educación integral», la «socialización», la reactivada «educación fisica para la salud», u otros eslóganes similares, le ha permitido mostrarse socialmente más plausible. Así, junto a las destrezas corporales propiamente dichas - del tipo y condición que en cada contexto y momento político hayan sido- todas las formulaciones institucionales de la materia han invocado a alguna clase inespecífica de valores tales como la autorrealización, la autosuperación, el autoconocimiento, etc., que, unidos a las también inespecíficas aptitudes sociales, afectivas o cognitivas, han permitido salvaguardar la continuidad de los modelos dominantes y, sobre todo, la han protegido de la crítica ante lo que podría ser visto como una dilapidación del tiempo escolar. Pero esta capitalización intensiva de propiedades no parece sino un mero engrosamiento retórico que parece encaminado a ocultar la deriva y la inoperancia pedagógica de las técnicas, las habilidades y las capacidades en las que instruye y, por añadidura, a ocultar el carácter impositivo y arbitrario del material ideológico, emocional y práctico del cuerpo que dichas técnicas, habilidades y capacidades llevan implícitas en la propia realización (Vicente, 2007b). Demasiados objetivos y, sobre todo, demasiado ambiguos; demasiado dispersos y trascendentes, teniendo en cuenta la escasa relevancia y significación que, de hecho tiene, en relación a todas las aptitudes y los valores que se enuncian, superar o no los tests de capacidad física que en tantas escuelas e institutos se imponen como condición para superar la asignatura y que tiene como resultado cierta homogeneización de la representación y uso cultural del cuerpo. Muy especialmente, teniendo en cuenta la escasa relevancia que tienen dichas pruebas y, en general, los contenidos en los que se apoyan, los cuales responden a una elaboración selectiva de prácticas corporales escasamente representativa de los intereses y expectativas (en relación con las perspectivas clase social, de género, o de cultura) de un alumnado cada vez más diverso. No se puede olvidar a este respecto que la escuela, si bien es un lugar al que van todos, en absoluto ha sido construida por todos, no es de todos ni, por definición, responde a las necesidades de todos.

Se podría decir, a este respecto, que el discurso de la educación física se ha preocupado más por establecer lazos de unión entre la escueta instrucción que tradicionalmente ha impartido y un ambicioso ideario formativo antes que dotar a la materia de elementos instructivos cuya significación cultural y social fuera verdaderamente relevante para los escolares, fueran cuales fueren sus condiciones, intereses, necesidades y expectativas con respecto a los usos del cuerpo y, sobre todo, teniendo en cuenta precisamente la gran diversidad de condición de estos. En ese sentido, aunque ya esté prácticamente desterrada la imagen del profesor de educación física colgado de un silbato, un cronómetro y un cuaderno de notas, pasando formularios de capacidad (antes, durante y después de sus enseñanzas), ilustra muy bien de una parte de la historia de la materia y de los referentes que aún siguen informando sus prácticas: la combinatoria del control infinitesimal de tiempo y la organización de la actividad colectiva en aras de una experiencia corporal que sigue siendo la retórica pedagógica que legitima la ética y la estética de la eficiencia, la obediencia y del orden medidos a través de logro deportivo o similar y donde la fácil trasgresión del grito, la risa, la escapada circunstancial o el escaqueo permiten mantener el espejismo de la educación física como materia que rompe la continuidad coercitiva de la institución escolar. Sin embargo, bajo la ilusión de la explosión libertaria del cuerpo que se mueve, la educación física se muestra como un espacio de visibilidad absoluta del sujeto, un espacio de constante tutelaje-muy especialmente ideológico-justamente porque, a diferencia de otros espacios académicos donde el cuerpo no importa, en ella el cuerpo es lo permanentemente visible, lo permanentemente actuado, lo continuamente regulado, lo constantemente objetivado. Si en la educación física estar es estar corporalmente-actuando, si pensar es moverse, si la conciencia es pararse y sentir, etc., no cabe duda, el ejercicio físico, adopte la modalidad que adopte, se configura como una prosaica ceremonia de confesión en la que es preciso moverse, moverse ante los demás y moverse bien: exhibición ostentosa de los más diestros, los mejor dotados, los más virtuosos cumplidores del régimen, pero también vergonzante muestra del desmañado, el flojo, el remolón, el torpe, el gordo y sobre tantos otros que como ellos sufren, en gran medida, la desposesión de su propio cuerpo.

\subsection{Desubjetivación del cuerpo}

El segundo de los tópicos en torno a la corporalidad que produce la educación física condice estrechamente con la concepción sustancialista de la realidad de manera que, por ejemplo, la desigualdad de clase social o de capital cultural y económico se reescriben como diferencias de mérito natural, o la desigualdad social de género se reducen a diferencias de caracteres sexuales. El sustancialismo considera el cuerpo como una entidad meramente biológica y mecánica enclavada en una sociedad, antes que una realidad social propiamente dicha. Una entidad cuyos atributos-objetivables mediante variables orgánicas y mecánicas, incluso, psicológicas-permitirían tratarla como «cosa» genérica, como algo dado por la naturaleza, siendo la educación física siempre, y se diría que sólo, el conjunto de actuaciones encargadas de producir en ese cuerpo «natural» las condiciones necesarias para su desenvolvimiento y su adaptación en -y a-cada contexto. Es decir, siendo la educación física el conjunto de actuaciones para su «puesta a punto» dando por buenos, también, 
muchos de los elementos de la vieja concepción mecanicista del cuerpo fundada sobre los principios del racionalismo cartesiano. Es lo que definiría como la desubjetivación del cuerpo en el sentido de que la preponderancia del discurso biológico y su afán por resaltar los atributos objetivables del cuerpo, termina por invisibilizar los rasgos subjetivossociales, culturales, ideológicos, etc.- de la corporalidad. Reduce la pluralidad social de los cuerpos al cuerpo unitario y genérico; desconfigura las corporalidades para reconfigurarlas sintéticamente en el cuerpo abstracto, el cuerpo «resumen», que tan bien representa el atlas anatómico que frecuentemente preside las paredes del gimnasio escolar o los murales del departamento de educación física.

Como la educación física no puede y, tal vez, no está interesada en atender la diversidad que la subjetividad corporal impone tanto en términos de género, como de clase social, como de etnia y en general de cultura, ha resuelto configurar el cuerpo escolarmente educable mediante la abstracción en los conceptos universales que la ciencia positiva proporciona; es decir, mediante la extirpación de los significados implícitos y explícitos de los rasgos corporales, mediante la desposesión de las necesidades y de las expectativas particulares o, lo que es lo mismo, mediante la homogeneización somática. La educación física construye, así, el cuerpo sin historia, el cuerpo físico, del que importa, sobre todo, su adecuación a los discursos y a los recursos escolares: un cuerpo culturalmente abstracto, existencialmente vacío de contenido y políticamente disponible (Vicente, 2006).

Un cuerpo culturalmente abstracto, porque frente a la variabilidad identitaria que proporciona la experiencia y los aprendizajes corporales concretos en la discontinuidad y conflictividad vital de lo cotidiano, se ve acuciado por la permanencia sustancial y seguridad racional de la anatomía, por la regularidad del recurso didáctico, por la unicidad de las estructuras de aprendizaje institucional y por la conformidad a los esquemas hegemónicos de consumo corporal, pero que disocia los aprendizajes del cuerpo de la vida cotidiana y sus requerimientos. Un cuerpo existencialmente vacío de contenido, porque la lógica de la escuela, a la que como se ha dicho van todos pero que de ninguna manera es de todos, prescribe, como condición de aprendizaje gradual, sistemático, metódico y evaluable la disolución de todos y cada uno de los rasgos somáticos de inserción histórica; en cierto modo, y en aras de la igualdad administrativa, exige el borrado de la memoria tanto personal como social y cultural del cuerpo, lo que permite la reordenación de las capacidades y habilidades esperables de acuerdo con los esquemas de representación y práctica instrumental de la agencia escolar. Dichas cualidades subvierten la diversidad en una pura diferencia de grado de cualificación que, por lo demás, exalta el rango a partir de la aptitud, y tal vez de la actitud, demostradas. Y, finalmente, un cuerpo políticamente disponible, porque la experiencia corporal es siempre un espacio de producción ideológica de modo que, una vez abstraídos los cuerpos en el concepto y despojados de su identidad más esencial, la política, queda apto también para recibir la experiencia corporal posible en la educación fisica: la experiencia definida por el lenguaje y los esquemas de verdad escolares siempre en consonancia con los postulados éticos, estéticos, morales e ideológicos de la clase dominante: la burguesía próspera, culta, deportiva y saludable; mejor, la burguesía consumidora de prosperidad, cultura, deporte y salud.

La desubjetivación del cuerpo, la redefinición orgánica de este, es tributaria en gran medida de un proceso de medicalización ya viejo pero que en las últimas décadas ha hecho mella en prácticamente todas las esferas de la vida cotidiana (Vicente, 2007a). La medicalización no sólo constituye un lenguaje para los asuntos del cuerpo sino que, sobre todo, impone un estilo de vida y una concepción general del mundo que, entre otras servidumbres, supone una renuncia cada vez más importante a la libre decisión sobre el propio cuerpo en favor de una autoridad pericial que ha derivado en una cada vez más presionante ordenación y normalización de la vida de los individuos; ordenación y normalización que se sirve de la representación del cuerpo un espacio neutro y racional, como la máquina humana, sobre la que se puede actuar, sí, pero donde las posibilidades de intervención sobre él, incluso las de índole didáctica, quedan estrictamente sometidas a las leyes de la fisiología y de la física) con el objeto de producir «mejoras» entendidas estas como requisitos del desarrollo, el perfeccionamiento, la adaptación, el incremento de la eficiencia fisiológica o mecánica de cada sujeto. Aquí, los conflictos que la diversidad social ocasiona a la escuela quedan resueltos ante la posibilidad cierta de la comparación de los cuerpos-organismo y, por lo tanto, ante la reveladora definición del cuerpo plenamente educado: el «cuerpo eficiente», el «cuerpo hábil» el «cuerpo sano», el «cuerpo en forma», el «cuerpo en equilibrio psicofísico», etc.; es decir, el cuerpo ajustado a los parámetros de la racionalidad positivista e instrumental en la que el diseño didáctico queda subsumido en un puro abastecimiento de «habilidades» y de «capacidades» físicas y, en consecuencia, la evaluación de la acción pedagógica, reducida a una mera valoración de dicha eficiencia, mediante cualquier prueba estandarizada de capacidad; una evaluación cuya pretendida neutralidad valorativa solidifica la percepción funcionalista de la realidad y coadyuva a la perpetuación de los saberes hegemónicos y del orden social establecido. A este respecto, es revelador el principio en el que, a fin de cuentas, se materializa la filosofia evaluadora de la educación física escolar: la filosofía de la comparativa de cuerpos objeto: cuerpos suficiente, insuficiente o deficientemente «finalizados», cuerpos provistos o no del contenido «motor» esperable en términos de eficiencia, cuerpos bien o mal adaptados. Filosofía comparativa donde, en última instancia, las diferencias individuales (reducidas a capacidades, aptitudes, competencia, etc.) se computan, no como variables socioculturales (de recursos simbólicos, de intereses, de expectativas, de representaciones, de significados, etc.), sino comouna variabilidad meramente técnica resultante de la ecuación entre el patrimonio biológico y el aprovechamiento de los medios técnicos (didácticos u otros) disponibles; medios que, por otra parte, son concebidos, construidos y aplicados a la consecución del ciudadano atleta, el ciudadano isotónico, disciplinado y eficiente, el ciudadano dispuesto y comprometido a mantener de por vida el hábito del ejercicio físico y a consagrarse a la búsqueda permanente del estado de salud.

\section{La ilusión didáctica: el conocimiento pericial como creencia}

Ni la concepción sustancial de la educación física -a partir de la cual, para muchos, su presencia en la institución escolar estaría justificada por sí misma-, ni la practicidad escudada tras una intensiva capitalización de propiedades formativas o bajo la consideración del sujeto pedagógico como una mera variable orgánica, podrían constituirse como mecanismos legitimadores de la materia escolar si el conjunto de tópicos que les da forma no estuviera entretejido por la trama de creencias (pedagógicas) profesionales; si no estuviera sostenida por una genérica cultura profesional confiada, más allá de las críticas institucionales o del desánimo personal de muchos profesores, en la que suponen una (incontestable) virtualidad educativa de la experiencia corporal bajo un adecuado diseño pericial. Es a esta clase de creencias y a ciertos dispositivos emocionales que operan en la configuración de la cultura profesional como inhibidores críticos a lo que aquí denominaré «ilusión didáctica», algunos de cuyos aspectos serán analizados en los siguientes subapartados.

\subsection{La practicidad en la educación física: sobre la pesca de} peces y otras especies pedagógicas raras

Es bien conocido aquél viejo proverbio chino: «dame un pez y comeré un día, enséñame a pescar y comeré todos los días»; alegato proeducativo donde los haya que, sin embargo, nada nos dice respecto de qué hacer, si llegado el caso, todos los peces del río se extinguieran devorados por una escurridiza especie anfibia, por la voracidad piscícola de la creciente población china o si, por el cambio climático, el río chino desapareciera con todos sus nutritivos moradores: ¿seguirían los maestros chinos enseñando a sus alumnos a pescar? Mi opinión es que si, llegado ese caso, y para entonces el sistema educativo chino estuviera adaptado a los modelos pedagógicos occidentales - por ejemplo el modelo pedagógico de la educación física-, la respuesta sería que sí; en las escuelas chinas se seguiría enseñando a los escolares a pescar, y entre 
otros loables razonamientos que pugnarían por mantener enseñanzas tan poco prácticas dentro del currículo estaría aquél que dijera que lo importante del arte de la pesca no reside en la utilidad de esta para conseguir los frutos fluviales sino en el arte mismo, en la grandeza que entraña el dominio de sus aperos y en las capacidades que desarrollaría para, por ejemplo, cazar canguingos o chibiritainas.

A este respecto, la ficción creada por Harold Benjamin (Peddiwel, 1939) propósito de la educación paleolítica constituye un contrapunto digno de tenerse en cuenta; resulta en especial ilustrativa de los dispositivos de conservación curricular de la educación física escolar a pesar de las constantes innovaciones y renovaciones a la que se ve sometida, al menos teóricamente: había una vez peces, caballos lanosos y tigres dientes de sable, y así la educación incorporaba sabiamente captura-de-peces-con-las-manos, reunión-de-caballos-lanosos y ahuyentamiento-de-tigres-dientes-de-sable-con-fuego. Más tarde las aguas se enturbiaron y la captura de peces se hizo más difícil, los caballos fueron reemplazados por rápidos antílopes y los tigres por osos. Aunque la comunidad se fue adaptando a las nuevas condiciones para sobrevivir y hubo quien pidió cambios en el curriculum, los sabios no oirían hablar de ninguna clase de cambio: con todos los intrincados detalles de la captura-de-peces, reunión-de-caballos y ahuyentamientode-tigres, el curriculum escolar estaba ya demasiado cargado como para añadir las caprichosas novedades y ringorrangos que supondría aprender a confeccionar redes, a colocar trampas para antílopes o a matar osos; al fin y al cabo, dirían los sabios ancianos, «no enseñamos a capturar peces con el fin de capturar peces; lo enseñamos para desarrollar una agilidad general que nunca se podrá obtener con una mera instrucción. No enseñamos a cazar caballos a garrotazos para cazar caballos; lo enseñamos para desarrollar una fuerza general en el aprendiz que nunca podrá obtener de una cosa tan prosaica como cazar antílopes con trampas. No enseñamos a asustar tigres con el fin de asustar tigres; lo enseñamos con el propósito de dar ese noble coraje que se aplica a todos los niveles de la vida y que nunca podría originarse en una actividad tan básica como matar osos... Habéis de saber que la esencia de la verdadera educación es la intemporalidad, que hay verdades que permanecen a través de las condiciones cambiantes y que el curriculum de dientes de sable es una de ellas» (Peddiwel, 1939, pp. 24-25).

Sobre el trasfondo del proverbio y la ficción, se plantean los dos grandes modelos de legitimación de la educación física; modelos en la práctica complementarios y a menudo con fronteras poco diáfanas, pero que según su predominio caracterizan, a su vez, dos tipos de creencias en torno a la materia.

Uno de ellos, tal vez el primero en el tiempo, de carácter más pragmático, es el modelo de legitimación extrínseca según el cual la educación física reportaría, con el cumplimiento de sus objetivos pedagógicos, beneficios en términos de habilidades, capacidades, disposiciones, aptitudes, actitudes, méritos, etc., que permitirían satisfacer algunas, o muchas de sus necesidades de orden somático: saltar, correr, resistir, meter muchos goles, cuidarse, etc. Otra cosa es que las capacidades y habilidades en las que forme valgan o no valgan al alumno; sean necesarias o no; estén ajustadas a las necesidades de todos, de unos pocos o de casi ninguno; sea discriminatorio por su concepción y selección, o no lo sea, etc., (de lo cual ya se ha discursado). La cuestión que se dirime es que este modelo de legitimación parte de unas supuestas necesidades respecto de las que se proveen y sistematizan ciertos aprendizajes que permitan satisfacerlas con mejores garantías a quienes se someten al proceso educativo. Aquí, el diseño y el desarrollo curricular se puede definir como un proceso de búsqueda de las necesidades e intereses de los alumnos, así como de los medios más eficaces para su consecución con todas las dificultades que supone la definición y la determinación de tales necesidades e intereses; especialmente, las dificultades que implica el hallazgo de los principios en virtud de los cuales puede y debe hacerse la jerarquía de necesidades y, en función de ella, la selección de objetivos, de contenidos, de actividades o de métodos: por ejemplo, la definición de «alumno», la definición de «necesidad», la definición de «sujeto (suficientemente) educado», la definición de «aptitud», etc.
El segundo modelo tiene mucho que ver con los que señalaba en el apartado denominado «capitalización intensiva de propiedades» y que, en última instancia, justifica la disciplina por un supuesto valor intrínseco de la materia o de las actividades que la conforman. Un valor indiscutido a cuyo reclamo se urde toda una red propiedades tan loables como indemostrable es que dichas propiedades no concurran de igual manera en actividades pedagógicas absolutamente diferentes, o simplemente en la actividad cotidiana fuera del espacio de asistencia y tutelaje escolar. Se trata de aquellas propiedades que se ajustan muy bien al desideratum «merece la pena ser aprendido», pero cuyo resultado es difícilmente constatable y, sobre todo, es dificilmente constatable la influencia que la acción pedagógica específica-en este caso de la educación física-pudiera haber tenido en dicho resultado. Algo que no desacredita totalmente dicha acción pedagógica específica-si se considera que (casi) cualquier producto cultural puede ser valioso-, pero sí anula el argumento por el que se pretende justificar la presencia obligatoria de la materia en la institución escolar, porque dicha presencia exige, además de la valía cultural genérica, otras condiciones de pertinencia entre las que la practicidad ha de ocupar, nos parece, un lugar de privilegio.

En la práctica, ambos modelos comparten espacio y funcionan indistintamente entre los profesionales, con mayor énfasis en uno u en otro según el momento, las condiciones, el contexto o según el destinatario de las explicaciones-si es que se trata de explicar a alguien el porqué de la educación física-. Lo que nos llama la atención es que el discurso de las justificaciones de carácter extrínseco (el discurso de las justificaciones pragmáticas) ha ido perdiendo espacio a favor de las de carácter intrínseco (aquellas que tienden a legitimar la materia por el valor que posee en sí misma o por el valor íntimo de sus contenidos: juego, deporte, experiencia corporal, etc.). Y aunque el motivo de tal perdida de espacio suele achacarse a la aureola reaccionaria que tiene todo pragmatismo-lo cual hace buscar, por lo menos a los profesores más activos e innovadores, justificaciones de más «alto valon» y razonamientos más complejos y elaborados como los que se pueden arañar a la filosofia, la antropología o a cualquier disciplina de corte «humanístico»-, en mi opinión, es una simple deriva argumental como consecuencia de la disolución de una practicidad obsoleta, poco atenta a las necesidades e intereses de la sociedad contemporánea y que la sátira de Harold Benjamin expresa de forma tan elocuente: una practicidad anclada en necesidades e intereses viejos y escasamente representativos para muchos de los integrantes de las generaciones que forman la sociedad contemporánea, unida a la secular resistencia institucional a prescindir de dichos contenidos e incorporar otros diferentes más acordes con las diversas realidades sociales y culturales. Resistencia a prescindir de dichos contenidos, considerados «sustanciales», «esenciales», «naturales», valiosos perse y que encubren una posición inmovilista mucho más reaccionaria que la practicidad a la que aquí se apela.

Tal vez convenga precisar aquí -aunque esté ya concluyendo el artículo- una cuestión de principios. Desde mi punto de vista, la practicidad como argumento justificativo de la pertinencia de una materia en la escuela no sólo no es algo reaccionario sino que es el único punto de apoyo sólido que permite legitimar la acción pedagógica que dicha materia implica. Otra cosa es qué elementos se consideran prácticos y cuáles no; bajo qué criterios se concibe la practicidad, con vista a qué clase de necesidades y, puesto que la población escolar no es homogénea, qué grupos se identifican con los patrones de practicidad interpuestos. Practicidad es atender las capacidades físicas y las habilidades que son necesarias para el desempeño eficiente en las prácticas lúdicas y de ocio o estéticas que demandan las clases acomodadas, si bien estas sean clasistas; también es practicidad atender las capacidades físicas que son necesarias para un desempeño no subyugante en la vida laboral y doméstica, por ejemplo, de un transportista, de una vendimiadora o de un estibador. Es evidente que ambos criterios de practicidad dicen cosas muy diferentes acerca de cómo debería ser la educación física. En otros términos; es en la identificación de los intereses y en la selección de los contenidos y los medios apropiados para satisfacerlos donde cabe la discusión sobre si la practicidad es o no reaccionaria, si es clasista, si es sexista, etc. Es preciso aclarar a este respecto que «practicidad» -0 
funcionalidad práctica y utilitaria de la educación física- no significa asunción de las concepciones funcionalistas de la sociedad que se han comentado críticamente más arriba de acuerdo con lo que Wright Mills (1999) denominaba practicidad liberal, conformista, acomodaticia y moralizadora; ni tampoco significa aceptación de los principios de eficiencia técnica de la razón instrumental cuya producción monopolística obedece a criterios de producción para el consumo y que el sociólogo norteamericano denominaba practicidad antiliberal, disciplinaria, controladora, autoritaria y economicista (Mills, 1999). Antes bien, constituye una apuesta por el sentido práctico de los aprendizajes corporales según criterios de producción (del cuerpo) para el uso propio, para el uso comunitario significativo y contextualizado y, en todo caso, para un uso libre de las servidumbres del consumismo del cuerpo; es decir, encaminados a la satisfacción de necesidades operativas comunes de gentes comunes en toda su diversidad: necesidades de destreza y habilidad simples pero útiles en la vida cotidiana, lejos de la hipertecnificación del ejercicio fisico, lejos de la cinética corporal abstracta, burocratizada, sistemática y regular y, asimismo, lejos de la institucionalidad de unas capacidades físicas racionalmente evaluables pero culturalmente desconectadas de la vida cotidiana para la mayoría. Constituye una apuesta, entonces, contra la exclusividad que suponen las prácticas corporales de clase, de cuyo contenido técnico o estético o ideológico se nutre el patrimonio distintivo la dominación cultural. A este respecto, en la medida en que el proyecto pedagógico implícito se oriente a la capacitación para el desempeño no sólo de actividades simbólicas, recreativas, estéticas, etc., sino también y sobre todo a la capacitación doméstico-laboral: asimismo, en la medida en que se dirija no a la perpetuación del sistema y sus desigualdades mediante la inculcación-reproducción de los modelos de acción hegemónica, sino a la transformación social mediante el desarrollo de capacidades críticas, deliberativas, de innovación y transformación, igualitaristas, con respecto a los usos y consumos corporales, la intervención educativa resultará eminentemente práctica. A fin de cuentas, «practicidad» es también aplicar los recursos pedagógicos a las necesidades culturales de emancipación, individual o colectiva, respecto de la presión que ejercen los usos y los valores de la cultura física dominante a menudo enunciados con términos de dudosa neutralidad moral e ideológica tales como autosuperación, autodominio físico, placer del movimiento, cuidado de sí mismo, etc. las cuales forman parte de la sensibilidad emergente de las clases urbanas acomodadas y de una relación del individuo con su cuerpo muy al gusto, y conforme a los intereses, de los miembros más consumistas de dichas clases.

A este respecto, volviendo a los tipos de justificación sobre los que aquí se debate, como complemento de las justificaciones intrínsecas, ajenas a la denostada practicidad, tiene lugar, paradójicamente, una hipertrofia del discurso técnico. A falta de discusión -especialmente discusión ideológica, pero también a falta de discusión moral y prácticasobre los criterios de selección de los objetivos educativos y sobre la utilidad de estos, dado el supuesto valor intrínseco de las acción físicoeducativa y de los contenidos de esta, se ha desarrollado todo un cuerpo argumental sustitutivo superficialmente técnico que en la práctica funciona como creencias de corte dogmático: la creencia en la eficacia técnica de la didáctica amparada en la verosimilitud que reporta la relación mecánica entre medios y fines, por muy endeble que sea, socialmente hablando, la operatividad o la practicidad de los fines; asimismo, la creencia según la cual dicha eficacia técnica-en el caso de ser cierta-agotaría el campo de las controversias pedagógicas de la materia. Es a esto a lo que denomino el conocimiento pericial como creencia; elemento fundamental de la ilusión didáctica que, combinando los principios ideológicos de la racionalidad instrumental -los principios de la eficacia productiva, no tanto para el uso como para el consumo especulativo-con los resortes emocionales del idealismo pedagógico, sólo puede contribuir a disolver un debate mucho más perentorio en la educación física: el debate del sentido (cultural, ideológico y político) de la materia escolar y de los contenidos en los que instruye sea cual fuere la eficacia con la que lo hace.
4.2. De la (supuesta) vastedad, suficiencia y neutralidad pedagógica del deporte

El conocimiento pericial como creencia, la ilusión didáctica, es, posiblemente, compartida por buena parte de los maestros y profesores de muchas materias escolares y tal vez podamos convenir en que está fuertemente relacionada con el carácter vocacional que siempre han mostrado las profesiones de la enseñanza. Sin embargo, es preciso resaltar que el carácter vocacional que manifiestan los profesores de educación física se ha visto incrementado por la tradicional relación-a veces identificación-entre la educación física y la práctica deportiva y el hecho de que, desde hace bastantes décadas, todas las cohortes de ejercientes hayan estado nutridas mayoritariamente por deportistas de mayor o menor nivel de implicación y dedicación, pero cuyo vínculo emocional, más que racional, con el deporte ha determinado la inclinación profesional hacia la educación física (Vicente, 2001). Dicho vínculo, que puede explicar el entusiasmo pedagógico en los profesores de educación física, ha podido constituir también una cortapisa para la reflexión crítica sobre la educación física como materia escolar y un freno a la innovación; sobre todo, un freno al análisis de la filosofía que informa y orienta los objetivos de la materia. En todo caso, ha podido suponer una limitación a la comprensión amplia de al materia y sus significados alimentada, en parte, por la común propaganda institucional que ha llegado a encumbrar al deporte a la categoría de actividad física más importante de nuestra sociedad y para el que no dejan de proclamarse sus beatíficas virtudes moralizadoras y normalizadoras.

Tal vez, una de las más arraigadas creencias que mantienen los profesores de educación física-aunque no solamente ellos-sea la que tiene que ver con la vastedad de la experiencia corporal deportiva y la virtualidad educativa que por sí misma procuraría la acumulación de dicha experiencia corporal; una vastedad a la que, en ocasiones, se suma la idea de suficiencia. Me refiero a la concepción, ya recurrente, de que la gran variedad de las especialidades deportivas, con la infinidad de técnicas corporales que dichas especialidades suponen, contiene una gama tan grande de técnicas y de acciones corporales para los alumnos, así como de gasto calórico, que con la sola práctica del deporte se podrían cubrir todas las expectativas de desarrollo de habilidades y capacidades físicas. No cabe duda de que la práctica deportiva implica un compromiso exhaustivo del cuerpo: en la mayor parte de los casos un gran compromiso energético y muchas ocasiones un importante compromiso técnico, perceptivo, coordinativo y de toma de decisiones; es en este tipo de argumentaciones donde la educación física trata de sostener un carácter eminentemente deportivo a lo que, en ocasiones, añade el papel formativo de la competición y de la autodisciplina que dicha competición impone.

Sin embargo, es necesario plantearse si el espectro de la motricidad que abarca la práctica de los deportes y el aprendizaje de sus técnicas, incluso si verdaderamente tuviera cabida en la escuela una amplia gama de especialidades -que no suele ser el caso por la evidente escasez de recursos espaciales, temporales, materiales y de formación del profesorado-, constituye, o no, un tipo de experiencia cuya capacitación tenga alcance más allá de la propia prestación deportiva. Mi opinión es que muy escasamente la tiene; considero que el carácter eminentemente abstracto de las técnicas deportivas supone grandes limitaciones formativas en aspectos tales como la creación, la expresión, la capacidad deliberativa, la introspección, la apreciación estética, etc., que a menudo figuran como estandarte de los objetivos de la educación física. Diría, incluso, que supone grandes limitaciones respecto del desarrollo de habilidades sociales en tanto que las relaciones que propicia el deporte están muy determinadas, en su mayoría, por el antagonismo competitivo. Por otra parte, el tan alto grado de especialización, y a menudo automatización, de la dinámica interna de las acciones deportivas deja escaso margen para que los aprendizajes deportivos tengan efectos prácticos significativos sobre las habilidades, físicas y no físicas, que los destinatarios de la acción pedagógica requerirán en la vida cotidiana. A este respecto, la teoría de la transferencia motriz nos parece sólo una coartada destinada a mantener el estatus pedagógico de unas prácticas 
que de otro modo serían consideradas escasamente formativas incluso cuando el deporte se auspicia bajo el subterfugio del juego.

A este respecto, no sería posible mantener la creencia en las virtudes pedagógicas del deporte si este no se hubiera hecho depositario de los más altos valores culturales mediante la aplicación mediática de tan extensas propiedades formativas y reformativas como las que acapara: enmienda para transgresores, moral para amorales, correctivo para delincuentes, revulsivo para vagos, pedagogía para inadaptados, etc. además de medicina para enfermos y entretenimiento para aburridos. Si ninguna práctica corporal existe de manera independiente de los gustos y de las propias necesidades del grupo social en cuyo seno aparece y a cuyos intereses responde, es evidente que el deporte ha de constituir alguna clase de ideología particular bajo la cual se configuran su modo de practicar lo que necesariamente opera como dispositivo de legitimación cultural al servicio de los intereses (culturales, sociales, económicos, etc.) de los grupos que lo imponen (Vicente, 1996, 1997, 2006): la clase dominante, la etnia dominante, el género dominante. No es esta la ocasión para extendernos en la crítica a la ideología deportiva, pero sirva sugerir una reflexión sobre el tipo de valores que supone y enseña la competición deportiva, así como el camino para llegar a ella: el entrenamiento intensivo, la renuncia ascética, la selección metódica y permanente; cierto cultivo del individualismo, no sin importantes dosis de agresividad, acompañados de lo que se ha dado en denominar el papel educativo del «ídolo deportivo» y que, desde mi punto de vista, constituye una modalidad pedagógica que lejos de fomentar el sentido crítico, la autonomía o la creatividad, etc., inculca el modelo social de las adhesiones incondicionales, del aprendizaje por imitación, de la ensoñación alienante de la gloria de otros, del culto al éxito y a la apariencia, etc. Por otra parte, los modelos deportivos, en cualquiera de sus facetas no se distinguen ni por tener estructuras democráticas ni un modo de funcionamiento igualitarista; más bien, se caracteriza por la verticalidad de sus estructuras, las cuales se imponen como requisito de las relaciones de autoridad que otorgan legitimidad a formas abiertas de discriminación como, por ejemplo, las de genero -que en otros ámbitos se combaten por inaceptables-, y a formas de discriminación no tan abiertas pero igualmente inadmisibles como las de clase o de etnia.

\subsection{La experiencia corporal como pretexto}

Evidentemente, las sensibilidades pedagógicas en torno a la educación física no se limitan en exclusiva a las que la enseñanza del deporte determina ni al desarrollo de capacidades y aptitudes definidas por lo deportivo, aunque estas sigan siendo hegemónicas. Muchas de las iniciativas denominadas innovadoras o alternativas han puesto sobre la mesa contenidos hasta hace poco escasamente relevantes en el conjunto curricular de la materia; incluso, algunas de ellas han encontrado refrendo en disposiciones normativas que, al menos en la letra, abogan por una educación física más allá del deporte, en aras de una formación corporal plural y diversa dando cabida, por ejemplo, a las actividades artísticas del cuerpo y expresivas en general. Nociones como cuerpo simbólico, cuerpo expresivo y comunicativo unidas a la bien arraigada idea de necesidad funcional de movimiento han ido otorgando relevancia a la categoría pedagógica de la experiencia corporal que ha permitido ir más allá del corto alcance que pudiera tener el dominio de una técnica corporal concreta-deportiva o no-y también más allá de la provisionalidad de la capacidad orgánica desarrollada. Todas ellas han contribuido a modificar algunos de los más acendrados presupuestos de la educación física tradicional, hasta el punto de que no parece que ningún discurso sobre la materia pueda prescindir, hoy, de la justificación que constituye la necesidad de experiencia corporal.

Sin embargo, dichanecesidad, indiscutible por lo genérica y ambigua, sirve para implantar actividades y para producir aprendizajes cuyos valores culturales y prácticos concretos pueden ser de muy distinta condición y, por lo tanto, de muy diferente significado; desde la práctica de libre juego hasta la carrera extenuante pasando por la danza, el deporte, el aprendizaje de una técnica manufacturera o la no práctica, todas proporcionan experiencia corporal pero, como ya se ha apuntado, imprimen signos muy distintos en la subjetividad y configuran modelos corporales también muy distintos. De donde dicha noción de experiencia, enunciada en abstracto, termina apelando sólo a un requerimiento acumulativo de «movimiento», de actividad física, donde lo que menos parece importar es la adscripción cultural-incluso política- que cada experiencia corporal concreta lleva implícitay, por lo tanto, la significación que produce en el sujeto.

No se puede perder de vista que toda experiencia corporal constituye una modalidad cultural de comprensión del cuerpo propio y de su relación con el mundo y con los demás; es un espacio de producción simbólica e ideológica, tanto más en la medida en que su administración pedagógica determina una clase, un tipo, de experiencia corporal que probablemente no todos deseen, de la que no todos disfrutan; un espacio de producción simbólica e ideológica cuyos frutos no sólo no son existencialmente significativos para todos sino que, según la clase social, el género, la etnia o la cultura propia, pueden llegar a sentirse como la agresión simbólica, y a menudo física, que muchos realmente sienten en sus cuerpos. Por añadidura, al servir de apoyo y justificación de la materia escolar, tiende a invalidar todo otro modo relacional y de experiencia con el cuerpo: especialmente los modos no dominantes $\mathrm{y}$, sobre todo, los no escolásticos de tratamiento de la corporeidad y del gesto.Aquí la ilusión didáctica consiste en primer lugar en la creencia de que toda experiencia corporal, por el hecho de poner al cuerpo en movimiento y producir sensaciones, intelecciones o emociones es deseable; $y$, en segundo lugar, que el saber pericial es capaz de determinar técnicamente la forma y modalidad de administración de la experiencia corporal de modo que sea de interés para los alumnos, sin contar con los alumnos o contando sólo retóricamente, y en genérico, con «el alumno».

$\mathrm{Si}$, de acuerdo con McLaren (1995), tenemos en cuenta que los cuerpos no son nunca espacios libres, que son lugares en los que se inscriben las marcas culturales organizando los actos y los afectos, y que históricamente tales inscripciones han operado como regulaciones prácticas al servicio del régimen dominante de la cultura, entonces ¿qué otro sentido que el funcional y técnico se pueden encontrar en los distintos elementos de la liturgia pedagógica del cuerpo?; ¿qué sentidoy qué significación tienen, por ejemplo, el uso del chandal, las zapatillas deportivas, el calentamiento, la ceremonia del ejercicio y tantos otros elementos rituales que conforman la puesta en escena de la educación física escolar? Por encima de la funcionalidad declarada que todos ellos poseen, constituyen, individualmente y en conjunto, un signo; un signo tomado en gran medida del código de las formas deportivas en cuyo interior adquiere su pleno sentido. Por encima de la «comodidad y libertad de movimientos» que reporta el atuendo deportivo, por encima de la «seguridad» que reportan las zapatillas deportivas, por encima de la «funcionalidad fisiológica» del calentamiento, etc., la escenificación de todo ello constituye, no se puede negar, una expresión de los principios que informan la educación física escolar y que comúnmente aceptamos. Lo mismo se podría decir del sentido y significación del paisaje escolar cuyos patios y gimnasios se adornan indefectiblemente con el consabido aparataje deportivo o, asimismo, de la porción seleccionada de los contenidos y hasta de la propia conceptualización y catalogación de las cualidades que la educación física trata explícitamente de desarrollar a través del tipo de experiencias corporales que las estructuras académicas permiten proveer.

Quiero decir que frecuentemente la experiencia del movimiento pedagógicamente administrada es un exponente ideológico de la sensibilidad dominante. Con gran probabilidad (sociológica), los principios y valores que la conforman no serían, sino los principios y valores de una fracción con capacidad para proponer e imponer su propio estilo de vida y en cuyo vértice se sitúa la estrategia por la cual tratamos -en las sociedades modernas y tecnológicas-de convencer y de convencernos de la necesidad de someternos a un proceso de acondicionamiento que es, sobre todo, un proceso de entrega a la mirada pericial del profesor bajo la ensoñadora ilusión de que este, al igual que el agricultor separa el grano de la paja, nos hace distinguir entre la buena y la mala práctica ofreciendo a sus alumnos sólo aquello que está pedagógicamente contrastado: relación de poder que se cierne 
inevitablemente sobre ese espacio privado e íntimo que es el cuerpo propio. Relación de poder que lo es más en cuanto que, como toda acción pedagógica, pretende perpetuarse como mirada, más allá de la inmediata observación física que se da en ese tiempo y en ese espacio institucional que es la escuela, con el objeto de asegurar la eficacia de la experiencia: una adherencia casi constitutiva a los modos en que corporalmente debemos ser, hacer, sentir; los motivos por los que debemos sufrir y disfrutar; las formas legitimadas de la corporalidad.

Muchas de las justificaciones pedagógicas de la educación física han encontrado raíz y respaldo en las modernas teorías psicobiológicas del desarrollo (Walkerdine, 1995), y la importancia que estas conceden al movimiento corporal en casi todos los órdenes. No se discute en este sentido que el movimiento sea necesario por más que favorezca o no la inteligencia, (creencia quemereceríaun ampliodebate); pero lajustificación de la educación física en este dominio, da un salto en el vacío y de la necesidad del movimiento deduce la imposición del ejercicio físico. Que el movimiento sea necesario no implica que lo sea el ejercicio físico ni ninguna modalidad cultural en la que este se manifiesta; en todo caso, no implica que sea necesaria su escolarización reducida a un proceso de modulación del desarrollo orgánico que encarna un sistema destinado, al fin y al cabo, a crear consumidores, competidores y contribuyentes satisfechos.

\section{A modo de conclusión}

Como reflexión final es preciso poner de relieve los intentos innovadores y transformadores que buena parte del profesorado, incluso algunas legislaciones, han ido poniendo en marcha en lasúltimas décadas. Es evidente que el conjunto de todo ello ha transformado en el medio plazo la materia académica y, con ella, el sentido de los aprendizajes corporales escolares. Sin embargo, desde una perspectiva amplia y de largo plazo tales cambios admiten una lectura algo más pesimista que aquella que trata de proyectar el pedagogo idealista; tales cambios han de verse también como una reacción estratégica de dominación ante los nuevos retos que tienen ante sí las clases dominantes para mantener y acrecentar su hegemonía. Serían, entonces, cambios que, parafraseando a Foucault (2005), se imponen para responder a exigencias de coyuntura pero que en conjunto se inscriben en el proceso de mutación general de administración disciplinaria.

A este respecto, indagar en los procesos de configuración de la educación física, incluso si auspiciara un debate abierto y generalizado sobre los mecanismos de legitimación de los contenidos, los objetivos, los métodos y la propia filosofía de la disciplina-como el aquí se ha tratado de plantear-, no es ninguna garantía de transformación. Según señalaba al principio, en la historia de la educación física de nuestro entorno y, en particular, de la española, tal vez no se ha vivido otra época de ebullición crítica teórico-práctica como la de las tres últimas décadas y, sin embargo, el tipo de cambios experimentados por la disciplina no pasan de ser, a mi juicio, leves y banales adaptaciones técnicas a los dictados de la moda que poco tienen que ver con los propósitos, a menudo enunciados, de significatividad de los aprendizajes corporales, emancipación, desarrollo del sentido crítico respeto a la diversidad cultural, aminoración de las desigualdades, etc. Son cambios que, desde mi punto de vista, tienen poco que ver con el desarrollo de la apreciación crítica de los usos diversos del cuerpo en una sociedad como la nuestra en la que el saber legitimo -y acomodado- exalta el cuerpo deportivo, el cuerpo lúdico, el cuerpo en forma, el cuerpo bello, etc., tal como lo perciben o lo sueñan las clases con capacidad para construir y difundir discursos y prácticas deportivas, lúdicas, de la forma física o de la belleza.

Sin embargo, no podemos quedarnos con los brazos cruzados esperando que la imparable fagocitación del pensamiento crítico por parte de los saberes técnicos y el conocimiento legitimado termine por invisibilizar a aquellos que en los procesos sociales de distribución de los recursos materiales y simbólicos para el uso del cuerpo han ido quedando en los márgenes de la cultura física legítima; tampoco, podemos esperar a que las bienintencionadas ilusiones pedagógicas de la sociedad bienpensante ahoguen las oportunidades reales para la igualdad mediante la aplicación formal y neutra de un inicuo procedimiento de igualdad de oportunidades que sigue descansando en la creencia de que el conocimiento que dispensa la escuela es neutro y su adquisición, nada tiene que ver con la clase social, la etnia-cultura, el género, etc. Algo que es especialmente relevante en el caso de la educación física, donde las concepciones dominantes sostienen que cuerpo es algo naturalmente dado. No podemos esperar, entonces, que análisis de esta clase provoquen un cambio sustancial pero sí, al menos, que el paulatino desvelamiento de los mecanismos de legitimación del conocimiento técnico que sustenta la educación física escolar contribuya a conservar el problema; es decir, que ayude a que el conflicto ideológico y político que supone intervenir en el cuerpo -en los cuerpos-y en sus aprendizajes no se disuelva, por saturación de la racionalidad instrumental y de las nociones funcionalistas que alberga, en un mero problema de ingeniería didáctica.

\section{Bibliografía}

Berger, P. y Luckmann, T. (2003). La construcción social de la realidad. Buenos Aires: Amorrortu.

Bourdieu, P.(1991). El sentido práctico. Madrid: Taurus.

Cagigal, J. M. (1979). Cultura fisica y cultura intelectual. Buenos Aires: Kapelusz.

Clement, J-P. y Herr, M. (1993).L'identitédel'education physisque scolaire au XXe siècle. Clermont-Ferrand:AFRAPS.

Corbin,A. (1991). El secreto del individuo. En Ariès, Ph. y Duby, G. (dir.) Historia de la vida privada (pp. 121-203). Madrid: Taurus.

Devís, J. (1996). Educación fisica, deporte y currículo. Madrid: Visor.

Elias, N. (1978). What is Sociology? Londres: Hutchinson.

Elias, N. (1989). El proceso de la civilización. Madrid: F.C.E.

Elias, N. (1990). La sociedad de los individuos. Barcelona: Península.

Fauché, S., Callède, J-P., Gay-Lescot J-L. y Lapagne J-P. (2000). Sports et identités. París: L'Harmattan.

Fernández-Balboa, J.M. (2003). Postmodernidad e investigación en la educación fisica. Ágora para la educación fisica yel deporte, 2-3, 5-22.

Foucault, M. (1991). La gubernamentalidad. En Foucault, M., Donzelot, J., Grignon, C., Gaudemar, J-P. de, Muel, F. y Castel, R. Espacios de poder (pp. 9-26). Madrid: La Piqueta.

Foucault, M. (1999). El orden del discurso. Barcelona: Tusquets.

Foucault, M. (2005). Vigilary castigar. Barcelona: Siglo XXI.

Grupe, O. (1976). Teoría pedagógica de la educación fisica. Madrid: INEF

Kirk, D. (1990). Educación fisica y curriculum. Valencia: Universitat de València. Mclaren, P. (1995). Pedagogía crítica y cultura depredadora. Barcelona: Paidós.

Mills, W. C. (1999). La imaginación sociológica. Madrid: F.C.E.

Parlebas, P. (1987). Perspectivas para una educación fisica moderna. Granada: Unisport.

Peddiwel, J.A. (1939). The Sabre-Tooth Curriculum. Nueva York: McGraw Hill.

Rodríguez, J., Amorrortu, R. Stangegaard, M., y Sánchez, J. J. (1988). La epistemología de la educación fisica en José María Cagigal. Motricidad, 2, 717.

Sergio, M. (1988). Epistemologia da motricidade. Lisboa: FMH.

Vázquez, B. (1986). La educación fisica en la perspectiva de las ciencias de la educación. Bilbao: Círculo Vasco.

Vicente, M.(1988). Teoríapedagógica de la actividad fisica: Bases epistemológicas. Madrid: Gymnos.

Vicente, M. y Brozas M.P.(1996).La disposición regulada de los cuerpos. Propuesta de un debate sobre el estatus de los juegos tradicionales». Apunts, 48, 6-16.

Vicente, M. (2001).Lamirada del otro: escuela, cuerpoy poder. Revista de Educación Física, renovar la Teoría y la Práctica, 84, 5-14.

Vicente, M. (2006). El cuerpo de la educación física, dialéctica de la diferencia. Revista Iberoamericana de educación, 39, 53-72.

Vicente, M. (2007a).La construcción de una ética médico-deportiva de sujeción: el cuerpo preso de la vida saludable. Salud Pública de México, 49 (1), 71-78.

Vicente, M. (2007b). El cuerpo sin escuela: proyecto de supresión de la educación física escolar y qué hacer con su detritus. Ágora para la educación fisica yel deporte, 4-5, 57-90.

Walkerdine, V.(1995). Psicología del desarrolloy pedagogía centrada en el niño. La inserción de Piaget en la educación temprana. En J. Larrosa, (ed.) Escuela, poder y subjetivación (pp. 79-54). Madrid: La Piqueta.

Wittgenstein, L. (1994). Los cuadernos azul y marrón. Barcelona: Planeta. 